\title{
Molybdenum(II) Diiodo-Tricarbonyl Complexes Containing Nitrogen Donor Ligands as Catalyst Precursors for the Epoxidation of Methyl Oleate
}

\author{
C. A. Gamelas ${ }^{1,2}$, P. Neves ${ }^{3}$, A. C. Gomes ${ }^{3}$, A. A. Valente ${ }^{3}$, C. C. Romão ${ }^{1}$, I. S. Gonçal- \\ ves $^{*}, 3$, M. Pillinger ${ }^{*}, 3$
}

${ }^{1}$ Instituto de Tecnologia Química e Biológica da Universidade Nova de Lisboa, Av. da República, 2780-157 Oeiras, Portugal

${ }^{2}$ Escola Superior de Tecnologia, Instituto Politécnico de Setúbal, 2910-761 Setúbal, Portugal

${ }^{3}$ Department of Chemistry, CICECO, University of Aveiro, 3810-193 Aveiro, Portugal

*igoncalves@ua.pt; mpillinger@ua.pt

Keywords: Molybdenum, Oxidative decarbonylation, Alkenes, Epoxidation, Methyl Oleate, Biomass conversion

\section{$1 \quad$ Introduction}

The use of molybdenum carbonyl complexes as precursors to molybdenum(VI) catalysts for the epoxidation of olefins has been intensively researched since 2003, when Abrantes et al. [1] reported that highly active $\left(\eta^{5}-\right.$ $\left.\mathrm{C}_{5} \mathrm{R}_{5}\right) \mathrm{MoO}_{2} \mathrm{Cl}$ catalysts $\left(\mathrm{R}=\mathrm{H}, \mathrm{CH}_{3}, \mathrm{CH}_{2} \mathrm{Ph}\right)$ could be generated in situ by reaction of the tricarbonyl complexes $\left(\eta^{5}-\mathrm{C}_{5} \mathrm{R}_{5}\right) \mathrm{Mo}(\mathrm{CO})_{3} \mathrm{Cl}$ with the oxidant tert-butylhydroperoxide (TBHP). Since then, several types of molybdenum carbonyl complexes have been studied, including cyclopentadienyl complexes [2], $\eta^{3}$-allyl complexes $\left[\mathrm{Mo}\left(\eta^{3}\right.\right.$ allyl) $\left.\mathrm{Cl}(\mathrm{CO})_{2}(\mathrm{~L})\right]$ [3], heptacoordinate tricarbonyl complexes $\left[\mathrm{Mo}(\mathrm{CO})_{3} \mathrm{I}_{2}(\mathrm{~L})\right][4]$ and tetracarbonyl complexes cis$\left[\mathrm{Mo}(\mathrm{CO})_{4}(\mathrm{~L})\right][5]$ (where $\mathrm{L}$ is a bidentate chelating dinitrogen ligand).

Despite the promising results obtained with the mentioned catalytic systems, there is room for further work in the field of selective epoxidation catalysis, with one of the most interesting aims being the development of efficient systems for the epoxidation of biorenewable olefins. Of particular interest are plant derived olefins such as (R)-(+)limonene, $\alpha$-pinene, and fatty acids and esters obtained from vegetable oils. In industry, epoxidized vegetable oils (EVO) are used as plasticizers, lubricants and as raw materials for the synthesis of a broad variety of polymeric materials. EVOs are commercially produced via a peracid process which has several drawbacks, such as low selectivity, the need to use excess $\mathrm{H}_{2} \mathrm{O}_{2}$, long reaction times and corrosion problems. The use of transition metal complexes as epoxidation catalysts may eliminate many of these problems.

As part of our ongoing exploration of molybdenum carbonyl complexes as catalyst precursors for the epoxidation of bio-derived olefins [6], we now wish to report on the use of the heptacoordinate molybdenum(II) tricarbonyl complexes $\left[\mathrm{Mo}(\mathrm{CO})_{3} \mathrm{I}_{2} \mathrm{~L}_{\mathrm{n}}\right](\mathrm{n}=1, \mathrm{~L}=$ bipy $(\mathbf{1})$, di-tBu-bipy $(\mathbf{2}) ; \mathrm{n}=2, \mathrm{~L}=$ pyridine $(\mathbf{3})$, 4-tertbutylpyridine (4)) in the catalytic epoxidation of methyl oleate (MO) using TBHP as oxidant [7].

\section{Experimental}

$\left[\mathrm{Mo}(\mathrm{CO})_{3} \mathrm{I}_{2}(\text { bipy })_{2}\right](\mathbf{1})$ and $\left[\mathrm{Mo}(\mathrm{CO})_{3} \mathrm{I}_{2}(\mathrm{py})_{2}\right](\mathbf{3})$ were prepared as in the literature [8]. The reactions of $\mathrm{MO}$ with TBHP (5-6 $\mathrm{M}$ in decane) were carried out at $75{ }^{\circ} \mathrm{C}$ in batch borosilicate micro reactors $(5 \mathrm{~mL})$, under magnetic stirring. The initial molar ratios of Mo:MO:oxidant were 1:100:152, and $1 \mathrm{~mL}$ of 1,2-dichloroethane (DCE) or 0.3 $\mathrm{mL}$ of the ionic liquid (IL) 1-butyl-3-methylimidazolium tetrafluoroborate ([bmim] $\mathrm{BF}_{4}$ ) were used as cosolvent. The catalytic reaction was monitored by GC and the reaction products were identified by GC-MS.

\section{$3 \quad$ Results and discussion}

The complexes $\left[\mathrm{Mo}(\mathrm{CO})_{3} \mathrm{I}_{2} \mathrm{~L}_{\mathrm{n}}\right](\mathrm{n}=1, \mathrm{~L}=$ bipy (1), di-tBu-bipy (2); $\mathrm{n}=2, \mathrm{~L}=$ pyridine (3), 4-tertbutylpyridine (4)) (Fig. 1) are readily prepared in good yields by replacement of the acetonitrile ligands in $\left[\mathrm{Mo}(\mathrm{CO})_{3} \mathrm{I}_{2}(\mathrm{NCMe})_{2}\right]$ by the nitrogen donor ligands. Complex $\mathbf{4}$ has not been previously reported.
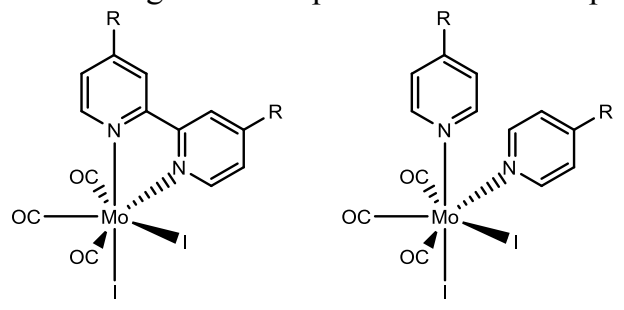

$\mathrm{R}=\mathrm{H}(\mathbf{1}), \mathrm{tBu}(\mathbf{2})$

Fig. 1 Catalyst precursors used in this work 
Complexes 1-4 were investigated as catalyst precursors in the liquid-phase epoxidation of MO with TBHP (in decane), at $75^{\circ} \mathrm{C}$. Methyl 9,10-epoxystearate (MES) was always the main product (Fig. 2), in up to $71 \%$ yield at ca. $80 \%$ conversion, $24 \mathrm{~h}$. By-products included methyl-9,10-dihydroxyoctadecanoate. Considerable differences in reaction rate (based on conversions at $6,24 \mathrm{~h}$ ) were observed for complexes $\mathbf{1 - 4}$, following the order $\mathbf{2}(65,78 \%)>$ $\mathbf{1}(47,72 \%)>>4(23,37 \%)>\mathbf{3}(16,25 \%)$.

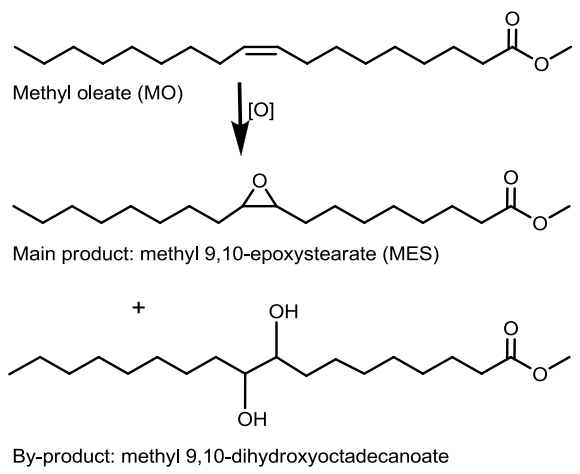

Fig. 2 Identified products in the reaction of MO with TBHP at $75^{\circ} \mathrm{C}$ using complexes $1-\mathbf{4}$ as catalyst precursors

The oxidized metal compounds could be isolated by scaling up the catalytic experiments in the absence of substrate. The FT-IR spectra of the oxidized compounds $1 *$ and $2 *$ match those reported previously for $\left[\mathrm{MoO}_{3}\right.$ (bipy)] and $\left[\mathrm{Mo}_{8} \mathrm{O}_{24}(\text { di-tBu-bipy })_{4}\right]$, respectively $[3,5]$. For $3 *$ and $4 *$, the spectra are consistent with the presence of the pyridinium $\beta$-octamolybdates $\left(\mathrm{C}_{5} \mathrm{H}_{5} \mathrm{NH}\right)_{4}\left[\mathrm{Mo}_{8} \mathrm{O}_{26}\right]\left(3^{*}\right)$ and $\left(\left(\mathrm{CH}_{3}\right)_{3} \mathrm{CC}_{5} \mathrm{H}_{4} \mathrm{NH}\right)_{4}\left[\mathrm{Mo}_{8} \mathrm{O}_{26}\right]\left(4^{*}\right)$. The reaction of MO with TBHP in the presence of $1^{*}-4^{*}$, at $75^{\circ} \mathrm{C}$, was much faster than that observed for the corresponding precursor complexes 1-4. These results may be partly due to the fact that the primary oxidative decarbonylation step is not required for the (pre-oxidized) complexes $1 *-4 *$.

Since $1 *$ acts as a homogeneous catalyst, the development of procedures for its separation from the reaction mixture and reuse is desirable. In the present work, $1^{*}$ was dissolved in an $\mathrm{IL},[\mathrm{bmim}] \mathrm{BF}_{4}$, which poorly dissolves the substrate and products. This IL-based catalytic system led to $86 \%$ MES yield at $89 \%$ conversion, $24 \mathrm{~h}, 75^{\circ} \mathrm{C}$.

\section{Conclusions}

This work has shown that molybdenum(II) diiodo-tricarbonyl complexes containing either monodentate or bidentate nitrogen donor ligands are convenient, easy to prepare precursors to oxomolybdenum(VI) catalysts, for the selective epoxidation of MO using TBHP as oxidant. Reaction with the oxidant TBHP results in oxidative decarbonylation and loss of the iodo ligands, giving the one-dimensional molybdenum oxide/bipyridine polymer $\left[\mathrm{MoO}_{3} \mathrm{~L}\right]$ for $\mathrm{L}=2$,2'-bipyridine, octanuclear $\left[\mathrm{Mo}_{8} \mathrm{O}_{24} \mathrm{~L}_{4}\right]$ for $\mathrm{L}=4,4$ '-di-tert-butyl-2,2'-bipyridine, and the pyridinium $\beta$-octamolybdates $(\mathrm{LH})_{4}\left[\mathrm{Mo}_{8} \mathrm{O}_{26}\right]$ for $\mathrm{L}=$ pyridine or 4-tert-butylpyridine. For the catalyst $\left[\mathrm{MoO}_{3}\right.$ (bipy)], the use of an IL as cosolvent facilitates the separation of the reaction products. The catalyst is fairly stable and recyclable in the IL medium, without significant drop in catalytic performance.

\section{Acknowledgements}

We are grateful to the Fundação para a Ciência e a Tecnologia (FCT), QREN, FEDER, COMPETE, the European Union and the Associate Laboratory CICECO (Pest-C/CTM/LA0011/2011).

\section{References}

[1] M. Abrantes, A.M. Santos, J. Mink, F.E. Kühn, C.C. Romão, Organometallics 22 (2003) 2112

[2] F.E. Kühn, A.M. Santos, M. Abrantes, Chem. Rev. 106 (2006) 2455, and references cited therein

[3] C.A. Gamelas, A.C. Gomes, S.M. Bruno, F.A.A. Paz, A.A. Valente, M. Pillinger, C.C. Romão, I.S. Gonçalves, Dalton Trans. 41 (2012) 3474

[4] M. Vasconcellos-Dias M, C.D. Nunes, P.D. Vaz, P. Ferreira, P. Brandão, V. Félix, M.J. Calhorda, J. Catal. 256 (2008) 301

[5] A.A. Valente, J.D. Seixas, I.S. Gonçalves, M. Abrantes, M. Pillinger, C.C. Romão, Catal. Lett. 101 (2005) 127

[6] T.R. Amarante, P. Neves, C. Tomé, M. Abrantes, A.A. Valente, F.A.A. Paz, M. Pillinger, I.S. Gonçalves, Inorg. Chem. 51 (2012) 3666

[7] C.A. Gamelas, P. Neves, A.C. Gomes, A.A. Valente, C.C. Romão, I.S. Gonçalves, M. Pillinger, Catal. Lett. 142 (2012) 1218

[8] P.K. Baker, S.G. Fraser, Inorg. Chim. Acta 116 (1986) L3 